\title{
A SUPERFÍCIE PERSISTENTE DO COMEÇAR: ESCRITA-LEITURA EM MARIA GABRIELA LLANSOL
}

Jonas Miguel Pires Samudio*

RESUMO: Apresentamos, a partir de fragmentos de Inquérito às quatro confidências, de Maria Gabriela Llansol, uma reflexão acerca da escrita-leitura, partindo de uma articulação entre o texto Ilansoliano e o texto bíblico, sobremaneira o mito edênico. Objetivamos acompanhar o modo como o texto de Llansol estabelece um encompanhar o modo como o texto de Llansol estamando, confrontá-los e avançar na compreensão e na experiência da escrita-leitura como anterior a todos os inícios.

PALAVRAS-CHAVE: Escrita; Mito edênico; Maria Gabriela Llansol. *alfjonasss@yahoo.com.br

Formado em Filosofia Teologia e Letras, com Mestrado em

Estudos Literários (UFU), atualmente cursa o Doutorado em Teoria da Literatura e Literatura Comparada (UFMG), com pesquisa sobre Maria Gabriela Llansol.

RESUMEN: A partir de fragmentos de Inquérito às quatro confidências, de Maria Gabriela Llansol, presentamos una reflexión acerca de la escrita-lectura, en una articulación entre el texto llansoliano y el texto bíblico, sobretodo el mito edénico. Objetivamos acompañar la forma como el texto de Llansol establece un encuentro con esa tradición para, no confirmándola pero confrontándola, avanzar en la comprensión y en la experiencia de la escrita-lectura como anterior a todos los inicios.

PALABRAS CLAVE: Escrita; Mito edénico; Maria Gabriela Llansol. 
1. BLANCHOT. La escritura del desastre, p. 46. Tradução nossa.
"Escritura fora da linguagem, quiçá nada mais que o fim (sem fim) do saber, fim dos mitos, erosão da utopia, rigor da paciência premida". ${ }^{1}$ A afirmação de Maurice Blanchot, nossa entrada nesse texto, aponta, a partir de La escritura del desastre, a escrita da queda do astro, para o fim, quiçá o fim sem fim, dos mitos. Se o "fim" deles, estaríamos, talvez, por determinados modos de escrita, propensos a, desatando a relação com determinados conteúdos da cultura, estabelecer um contato com outras imagens. Se o "fim (sem fim)", certamente, o que se abre na cena escrita é, não tão somente uma adesão/confirmação de tais conteúdos, nem mesmo seu abandono; talvez, se passe a uma escrita do fim sem fim dos mitos, em que a literatura pode encontrar aquilo que, de cada narrativa, texto imagem, persiste em ser contado, e o faz pela impossibilidade de o ser em definitivo: o próprio começar.

Em tal singular relação com os mitos, a escrita pode, com eles, estabelecer encontros de intensificação imagética, deslocando aquilo que, em primeira ordem, se pretendia, pretensamente, expressar/ensinar a partir das narrativas míticas. Nesse sentido, apresentamos, a partir de fragmentos de Inquérito às quatro confidências, de Maria Gabriela Llansol, um pensamento sobre a escrita-leitura que parte de uma articulação entre o texto llansoliano e o texto bíblico, sobremaneira o mito edênico. Com isso, intentamos acompanhar o modo como a autora portuguesa estabelece um encontro com textos dessa tradição para, não confirmando suas leituras costumeiras, antes, confrontando-as, avançar na compreensão e na experiência da escrita-leitura como anterior a todos os inícios.

Em Inquérito às quatro confidências, sexo e leitura são as imagens da criação que, doados no humano Jardim do Éden, se dão como um segredo:

creio que a leitura

é o acto sexual por excelência. Penetra,

atravessa, transubstancia. É o órgão dos

carismas do viator-faber. Sempre a mística

os quis separar do seu órgão - o que teve

efeitos terríveis - admitindo, todavia,

que carismas e união com Deus não eram sinônimos.

Exatamente como não são sinônimos

sexo e amor. São potências, sabores,

forças experientes e eficazes. Era importante

que permanecessem no seio da bênção.

Mas todos os carismas foram dados ao humano

Jardim do Éden. Separá-los do seu órgão

é enfraquecer o livre arbítrio. Eram

eles que pairavam

à superfície das águas

o segredo do há. ${ }^{2}$
2. LLANSOL. Inquérito às quatro confidências, p. 95, destaques no original. 
3. As figuras Ilansolianas, imagensnoções, são grafadas, nesse texto, em itálico. Legência pode ser compreendida como a proposição llansoliana de leitura-escrita: "quem lê sabe que flutua uma linguagem dentro da linguagem quem lê sabe que, a nosso lado, a quem le sabe que, a nosso lado, a
leitura desenha, com uma latitude selvagem inaudita, a grafia de uma outra história que, por vezes, se confunde com a nossa;/ quem lê sabe que um livro é um não saber que, quando se desvenda, volta, por desejo, ao seu alvo imaginário" por desejo, ao seu alvo imaginário a linguagem, p. 16): em que temos a linguagem, p. 16); em suma, de qualquer forma de podor, de qualquer forma de poder, da de habitar os vários mundos e partilhr os vários mundos pagente seria, então, aques. experîncia

4. CASTELLO BRANCO. Nuvens de pensamento branco, p. 230.

5. A figura Há aparece, sobretudo, a partir de Inquérito às quatro confidências, livro que "é necessariamente uma montagem Sobre cada texto escrito no decurso dos meses era precis realizar um trabalho que
desenhasse uma linha de fulgor, >>>
Várias são as referências, nesse fragmento de 18 de julho de 1995, à cena da criação do livro do Gênesis. Tais referências, contudo, não se apresentam à guisa de confirmação do que é afirmado pelo texto bíblico; antes, sob a legência, ${ }^{3}$ lemos o Jardim do Éden e a bênção dada aos humanos nele postos, bênção que articula sexo e leitura, o viator, aquele que caminha, e o faber, aquele que faz. Ademais, o sexo de ler, figura operativa de leitura e escrita, traz os dois carismas, os carismas do poeta, ${ }^{4}$ caminhar e fazer, mostrando-os como presentes a todo início, "à superfície das águas". O poema, como caminho feito pelo e no corpo, paira, como "segredo do há". ${ }^{5}$

No princípio, está o poema. Se "o segredo do há" paira sobre as águas, tal imagem evoca outro poema de princípio, e um poema que marca, no Ocidente, a trajetória do pensamento e da religião. Como vemos:

${ }^{(1)}$ No começar, Deus criando

O fogoágua e a terra

${ }^{(2)}$ E a terra era lodo torvo

e a treva sobre o rosto do abismo

E o sopro-Deus

revoa sobre o rosto da água

${ }^{(3)}$ E Deus disse seja luz

E foi luz
${ }^{(4)}$ E Deus viu que a luz era boa

E Deus dividiu

entre a luz e a treva

${ }^{(5)}$ E Deus chamou à luz dia

è treva chamou noite

E foi tarde e foi manhã

dia um. ${ }^{6}$

No "dia um", quando Deus diz-faz "o fogoágua e a terra", e "a luz", separando-a da "treva”, marcando a temporalidade do cotidiano, o "sopro-Deus" pairava sobre as águas primordiais. Como o "segredo do há", o "sopro-Deus" pairava. "SoproDeus", em hebraico, é ruah, palavra de gênero feminino 7 que, partindo de inúmeros significados, tais como vento, sopro, vitalidade, e hálito, vem a se configurar como o "vento emitido por Deus, bramindo de encontro ao oceano primitivo, de sorte que o mundo não teria sido imaginado sem a presença de Deus, nem mesmo antes da criação". ${ }^{8}$ Ademais, ruah, traduzido para o grego como pneuma, e para o latim como spiritus, gradativamente, se identifica com o Espírito Santo, terceira pessoa da Trindade, que, na afirmação do teólogo Hans Urs von Balthasar, é "a reciprocidade da entrega, em virtude da qual e em primeiríssima instância a entrega tem sentido [...] em Deus, entrega absoluta por excelência: o produto único do dar e do receber divinos, o Espírito de amor,
5. >>> e a projectasse sobre um ser humano que morrera" sonho de que temos a linguagem, p. 7, destaques no original). Assim considerando a morte de Vergílio Ferreira e seu caminho para tornar-se figura, o Há, conforme entrevista da autora, "e o existente, e o que existe, e o que há, é o que há de manhã, à tarde, à noite, através dos meses, através do tempo, através do espaço etc" (Entrevistas, p. 62), em suma, o que permanece daquilo de um corpo como escrita-pensamento. Para uma maior compreensão, sugerimos a leitura de nossa dissertação de mestrado, em que realizamos uma leitura de Inquérito, a partir da figura Há: SAMUDIO, Jonas Miguel Pires. $O$ há de escrever: a poética figural em Inquérito às quatro confidências, de Maria Gabriela Llansol.

6. CAMPOS. Bere'shith. Gn1, 1-5, p. 45. Para os textos bíblicos arrolados, procuramos por traduçoes que os apresentem sob a forma poética.

7. BLANK. Espírito Santo/ Pneumatologia, p. 243

8. DAUTZENBERG. Espírito, p. 127. 
9. BALTHASAR. Ensayos Teológicos: IV Pneuma e Institución, p. 31. Tradução nossa.

10. LLANSOL. Lisboaleipzig I, p. 121.

11. LLANSOL. Inquérito às quatro confidências, p. 137, destaques no original. em certa maneira, a quintessência divina". ${ }^{9}$ Contudo, sabendo que o texto llansoliano promove uma emigração para um lugar de pensamento que, ainda que lembre a experiência de Deus, está "fora de todo contexto religioso, ou até sagrado", ${ }^{10}$ lemos que:

Com o meu pensamento ou então estendendo o meu pensamento, pego n'aquele livro - a Bíblia -, abro-o sobre toda a superfície da paisagem que alcanço. O livro está exausto, e descansa sobre tantas folhas; embrulho os meus dedos em algumas; meu espírito está longe, em tábua rasa; meu corpo está com ele - ali -, recebendo em pleno coração a rajada de sonhos inauditos do Deus que o escreveu.

- Que globo estranho - exclama O Mais Jovem.

- Sim. Que modo amargurado de entrar no mundo.

Por cima da paisagem espalham-se as Leis, os Livros Históricos, os Livros Proféticos, os Evangelhos, os Actos dos Apóstolos, as Epístolas, o Apocalipse que varreu mais do que os outros o altar-mor, antes de entrar no armário. Num livro e noutro livro, acho mal o mal.

“Não o encontro no seu jardim”, escrevo em letras pequeninas. Acho abissal que existam livros tão sem frinchas para deixar passar a luz. ${ }^{11}$
"Que modo mais amargurado de entrar no mundo", entrando pelos livros bíblicos exaustos, livros "sem frinchas para deixar passar a luz"; certamente, exaustos de se terem transformado em conjunto de leis, conjuntos fechados de leis que confirmam a preponderância de uns seres sobre outros. O que pode, então, um corpo sobre o livro exausto, para romper com a amargura dessa entrada que força até o limite o pacto de bondade que a todos une? Ler, na ruah, a figura do som pelos ares, "a parte mais íntima do som", pois "respiramos som", ${ }^{12}$ ou, ainda, ver ruah como espírito da restante vida. ${ }^{13}$ Restante vida que promove na textualidade Llansol, não a entrada no mundo por qualquer exaustão textual, por qualquer cansaço do texto, pelos nomes dos livros "d'aquele livro", em que "acho mal o mal" - talvez pelos dualismos simplificadores que se dão a ler, ou pelas interpretações do livro como "globo estranho", "espaço sem frinchas", ou, ainda, pela limpeza efetuada pelo último livro, a Escatologia como acabamento, o Julgamento Final, expressa pelo "Apocalipse"em que o pacto de bondade parece estar presente apenas nas primeiras letras; antes, no Texto, abre-se a possibilidade de entrar nos mundos pela liberdade de consciência e pelo dom poético, pelo vento que sopra e, soprando, diz-se como a voz sobre a "superfície das águas”, "o segredo do há”, ruah, o espírito que "repousava sobre o abismo, como uma ave que choca, para fazer surgir o mundo". ${ }^{14}$
12. LLANSOL. Parasceve, p. 177.

13. Restante vida, além do título de um livro de Maria Gabriela Llansol, é referida no prefácio de O livro das comunidades: "Todos cremos saber o que é o Tempo, mas suspeitamos, com razão, que só o Poder sabe o que é o Tempo: a Tradição segundo a Trama da Existência. Este livro é a história da Tradição, segundo o espírito da Restante Vida (...) O escrever acompanha a densidade da Restante Vida, da outra Forma de Corpo, que aqui vos deixo qual é: a Paisagem" (LLANSOL. O livro das comunidades, $\mathrm{p}$. 9-10). Assim, em concordânci com Erick Gontijo Costa, “[...] utilizaremos o significante Ilansoliano Restante Vida, que llansoliano Restante Vida, que momentos de sua obra, uma nomeação da vida que inscreve no texto, da vida que nele resta escrita" (COSTA. Curso de silêncio, p. 12, nota 5).

14. KOUBETCH. Da Criação à Parusia, p. 87. 
15. LLANSOL. Inquérito às quatro confidências, p. 98.

16. Segundo Maria Gabriela Llansol, sem circunscrever, de modo definitivo, a sobreimpressão não diz respeito, tão somente, à técnica textual/ discursiva de se relacionar obras; antes, é uma forma de habitar o mundo (Lisboaleipzig 1, p. 124) e uma técnica visual, em que paisagens deslizam umas sobre outras ( $p$. 129), e realiza-se, no texto, como uma interpenetração de várias cenas fulgor.

18. BÍBLIA DE JERUSALÉM. Gn 2, 8-9. Nota b.
Sobre a água primordial, o "sopro-Deus"; sobre a do texto, "o segredo do há". Água, imagem frequente na textualidade, imagem da superfície do texto, do rio da escrita, do texto que se encaminha para a leitura, da leitura que se dá em falhas de compreensão, em amplificação de movimentos circulares, em que o importante é o encontro, a partilha, o dom, a tão grande graça de textualidade:

- pensamento que ocorreu ao texto. Como poderia eu, ou poderíamos nós,

fonte de texto, fazer entrar na vossa água, água

que não criasse sede de mais água? A imagem líquida da criação sois vós.

Se vos aprouver, bebei. ${ }^{15}$

Olhamos a data do fragmento: 18 de julho de 1995. Ainda, a cena da criação, e da re-criação, em sobreimpressão. ${ }^{16} \mathrm{~A}$ leitura se dá ao lado da água, do incessante rio da escrita. Folheamos $\mathrm{Na}$ Casa de Julho e Agosto, livro que encerra a primeira trilogia de Maria Gabriela Llansol, a da Geografia de Rebeldes. ${ }^{17}$ Levados pela imagem de "geografia", nos voltamos para a localização do "humano Jardim", segundo o relato bíblico: em Éden, palavra compreendida como jardim, delícias e, inicialmente, estepe ${ }^{18}$ lemos que do meio do jardim brota um grande rio que, depois de irrigá-lo, " ${ }^{10}[\ldots]$ de lá se dividia formando quatro braços. ${ }^{(11)} \mathrm{O}$ primeiro chama-se Fison; rodeia toda a terra de Hévila [... ${ }^{(13)} \mathrm{O}$ segundo rio chama-se Geon: rodeia toda a terra de Cuch. ${ }^{(14)} \mathrm{O}$ terceiro rio se chama Tigre: corre pelo oriente da Assíria. O quarto rio é o Eufrates". ${ }^{19}$ Fixando-nos brevemente sobre a memória da outra leitura realizada, vemos:

Também é próprio da ousadia de semelhante itinerário designarem-me para assistir ao nascimento de um rio, seja o Tejo, o Tigre, ou o Eufrates.

Tejo-rio, na sua sombra, não se move. Quando lhe pergunto pelo lugar do nascimento dos rios, incluindo o Tigre e o Eufrates, responde-me que deve perigar minha razão, pois os rios não nascem,

brotam nos seus símbolos. ${ }^{20}$

Dos rios relatados no Gênesis, dois são geograficamente situados, Tigre e Eufrates, rios da Mesopotâmia, Crescente Fértil, lugar da origem da civilização; os outros dois, Fison e Geon, nunca foram encontrados: Johan Konings, em nota referente aos nomes dos rios, afirma que "os eruditos hoje desistiram de querer identificar e situar os dois primeiros rios; os dois últimos, Tigre e Eufrates, são conhecidos. Pode ser que se trate de uma geografia ideal da Terra Prometida" ${ }^{21}$ "Geografia ideal", uma espécie de "globo estranho", fechado, "sem frinchas para deixar passar a luz", lugar almejado que
19. BÍBLIA DE JERUSALÉM. Gn2, $10-13$.

20. LLANSOL. Na casa de julho e agosto, p. 101.

17. Chamada Geografia de Rebeldes, é composta, respectivamente, por: $O$ Livro das Comunidades; $A$ Restante Vida; Na Casa de Julho e Agosto.

21. BÍBLIA SAGRADA TRADUÇÃO DA CNBB. Nota referente a: $\mathrm{Gn} 2$, 10-14.
EM TESE
BELO HORIZONTE
v. 22
N. 2
MAIO-AGO. 2016
SAMUDIO. A superfície persistente do começar: escrita-leitura [...]
P. $245-254$ 
22. Consideramos, aqui - a partir da afirmação llansoliana: "não há literatura. Quando se escreve só importa saber em que real se entra, e se há técnica adequada para abrir caminho a outros" (Um falcão no punho, p. 52) - o real no sentido lacaniano, como o "desprovido de sentido" (LACAN. Seminário 23, o sinthoma, $\mathrm{p}$. 131), igualmente objeto de desejo da literatura (BARTHES. Aula, p. 22.), que, sempre fracassando em alcançá--lo, permanece justamente por isso, em procura. Consideramos, pois, com Lucia Castello Branco: "Se o real não é representável, mas apenas demonstrável, talvez seja possível concebermos um texto que [..] abandone definitivamente a representação e passe à demonstraça

decto postráa - do da força 'realista da foça 'reallsta dá letra, e năo de produzir outros efeitos e de realizar outros atos de escrita reitura: o corp'a'screver, o sexo de ler" (CASTELO BRANCO.

Nuvens de pensamento branco, p. 244.)

23. LLANSOL. Entrevistas, p. 58. não se situa no plano do realizável, lugar utópico; diferentes são os nomes situáveis do Tejo, do Tigre e do Eufrates, rios que não nascem, não por que sejam parte de uma "geografia ideal”, mas porque, talvez, se refiram, não aos símbolos que jogam os jardins edênicos para um espaço mítico, mas aos mundos possíveis que nascem do que resta dos símbolos: as suas letras; letras que, no atravessamento entre a escrita e o real, rasgam no texto o espaço edénico, cuja referência, de fato aqui, é o jardim do Gênesis, mas uma referência sobreimpres$s a$ no texto que, este sim, é rio de escrita, rio real de escrita real, rio de escrita do real. ${ }^{22}$

Retornemos para a imagem da criação entre união do sexo e da leitura. Lemos, em entrevista, quando Maria Gabriela Llansol comenta o fragmento citado, de 18 de julho de 1995

Eu penso que a leitura cria uma relação extremamente íntima com alguém. Alguém que lê profundamente é penetrado pelo que lê. E, digamos, essa penetração é uma penetração expansiva, não é uma penetração que fique ali para utilidade própria. [...] eu considero a leitura uma espécie de sexo, porque de facto penetra profundamente, penetra profundamente e reproduz. ${ }^{2.3}$

A cena da criação, em Inquérito às quatro confidências, é a relação entre sexo e leitura, e o texto é aquele que penetra expansiva e profundamente, reproduzindo, no corpo daquele que lê, a escrita, não ficção, mas "pulsão para o aprofundamento das fontes da alegria de viver" ${ }^{24}$ Com essa imagem ainda no campo da visão, nos voltamos para outro fragmento:

Outrora, quando me baptizaram, os meus padrinhos responderam "Sim" à pergunta "Renuncias a Satanás, às suas pompas e às suas obras?"

Hoje, ao escrever, eu respondo sempre "Sim" mas, na realidade, estou a responder a outra pergunta. A pergunta da tília e da lagartixa é totalmente diferente. "Renuncias à bênção?", é o que me perguntam, e

me pedem..$^{25}$

Renunciar à bênção humana do Jardim do Éden. Nosso olhar se volta, diante disso, para aquilo que, no relato do Gênesis, foi a maldição: tendo sido proibidos de comer da árvore do conhecimento do bem e do mal, Adão e Eva são tentados pela serpente; tendo respondido "sim" à tentação, são expulsos do Paraíso - não sem antes o homem ser declarado senhor e a mulher submetida a ele -, ao passo que a serpente recebe o castigo de estar abaixo de todos os outros seres: “14Então Iahweh Deus disse à serpente: 'Porque fizeste isso és maldita entre todos os animais domésticos e todas as feras selvagens. Caminharás sobre teu ventre e comerás poeira todos os dias de tua vida". ${ }^{26}$ A serpente foi, no decorrer dos tempos, associada ao Adversário de Deus, Satanás,
24. LLANSOL. Entrevistas, p. 55

25. LLANSOL. Inquérito às quatro confidências, p. 86.

26. BÍBLIA DE JERUSALÉM. Gn 3,1$11.14-15$
EM TESE
BELO HORIZONTE
v. 22
N. 2
MAIO-AGO. 2016
SAMUDIO. A superfície persistente do começar: escrita-leitura [...]
p. $245-254$ 
27. COUTO. Narrativas da criação, $p$. 39-40.

28. COUTO. Narrativas da criação, $p$. 40 .

29. O filósofo afirma: "A serpente representa, no próprio coração do mito adânico, a outra face do mal, que os outros mitos. mavi o mal que atrai e seduz o

homem. A serpente significa que o homem náo começa o mal.

continuar. Assim, para áçar é continuarara. Assim, pará além da projeção da nossa própria cobiça, a serpente simboliza a tradição de um mal mais antigo que ele mesmo. A serpente é o Outro do mal human'. RICOEUR. Le Volontaire et I'Involontaire, p. 29 tradução nossa. tanto quanto a todas as forças que impelem o coração humano a se afastar do reto caminho. António Couto afirma que a serpente cumpre a função ficcional e literária de apontar para a possibilidade e o desejo humanos de dizer não ao projeto de Deus, conjugando um animal ordinário rastejante e um personagem mitológico, cujo nome (nahash) evoca magia (nahash), adivinhação (nihesh) e idolatria (n'hosher). ${ }^{27} \mathrm{~A}$ última referência nos interessa sobremaneira, visto que liga a serpente aos cultos cananeus de fertilidade - daí o caráter eminentemente catequético e proselitista do relato bíblico-, nos quais a serpente era símbolo da virilidade, tanto por sua forma, quanto por sua costumeira agilidade em penetrar a terra, a Grande Mãe. ${ }^{28}$

Nossa discussão, aproximando as imagens de sexo e leitura como cenas da criação, trazendo ainda à tona a recusa da bênção, volta-se para um fato textual bastante ignorado (fato que é lido, por exemplo, por Paul Ricoeur, como metáfora do mistério da entrada do mal no mundo): ${ }^{29}$ a serpente, no texto, é um ser que fala; astuto, por certo, mas, ainda assim, um ser vivo, tal como a tília e a lagartixa. Antes da maldição, havia a proibição; com a maldição, veio a sujeição do animal e da mulher, da natureza, ao homem. Renunciar à bênção parece, pois, com a renúncia a qualquer prática linguageira baseada nessa impostura, substituindo o humano Jardim do Éden - e desconstruindo a tradição religiosa a essa ideia vinculada -, pelo espaço edênico, espaço em que a escrita prevalece desde antes de qualquer princípio mítico:

[...] se conseguires imaginar um espaço edénico que não esteja na origem do universo, como diz o mito; que seja criado no meio da coisa, como um duplo feito de novo e de desordem; que sempre existiu e não só no princípio dos tempos; que está correndo o risco de desaparecer aqui e a novidade de aparecer, além, incógnito e irreconhecível; que não é fixo, como sugere a tradição, mas elaborável segundo o desejo criador do homem, compreenderás o espaço edénico. ${ }^{30}$

Espaço edénico, lugar em que a serpente não precisa falar "como um ser humano" para ser ouvida, pois esse elemento narrativo, aproximado daquele em que a mulher é a primeira a "sucumbir", já desresponsabiliza o homem diante de seu livre arbítrio, dando-lhes "padrinhos" que façam qualquer renúncia e aceitação em seu lugar. A diferença, então, se situa no ponto em que a leitura, penetrando expansivamente e reproduzindo, tal como a serpente cananeia, o faz por decisão daquele que escreve, e escrevendo responde àquilo que, antes da bênção, existia: o fato de que:

Deus viu o seu feito no todo

e eis que era muito bom. ${ }^{31}$
30. LLANSOL. Entrevistas, p. 22.

1. CAMPOS. Bere'shith. Gn 1, 31 p. 49. 
32. LLANSOL. Inquérito às quatro confidências, p. 104.

33. Sobre a Paisagem, importante figura-noção da escrita de Llanso em intima relação com o vivo (todas as formas vivas, incluida convina, responsáveis pela vida) sugerimos a leituro da "Ética), sugerimos a leitura de "Etca da paisagem", de João Rocha, em que lemos: "Aqui, todo vivo escreve, pois toda' Escrever, no vivo, é cona escrita. Escrever, no vivo, é contaminar e ser contaminado pelo outro, é fazer das letras que restam desse embate os caminhos labirinticos de uma vida. E tais encontros não se dão somente entre humanos, pois, aqui, o homem é uma paisagem, isto é, ele é um 'vivo', como qualquer outro, no meio do 'vivo'. $E$, nesse campo, uma ética desponta no horizonte: a ética da paisagem" (ROCHA. Ética da paisagem, p. 96-97).

34. LLANSOL. Causa Amante, p. 160
Ou, na legência, viver o pacto de bondade, o elo que, fora da bênção, se dá entre todas as formas do vivo: "o contacto de bondade que nos liga" ${ }^{32} \mathrm{E}$, nesse pacto, não há hierarquização dos seres, não há necessidade de sua antropomorfização, eles não precisam entrar no mundo da linguagem para assumirem a escrita. Eles, serpente, tília, lagartixa, já têm seu modo próprio de vibrar na escrita dos mundos: na paisagem. ${ }^{33}$

Ademais, como "à superfície das águas", "no começar", persiste a escrita, animal prevalente a todo encontro com ele:

era uma vez um animal chamado escrita, que devíamos, obrigatoriamente, encontrar no caminho; dir-se-ia, em primeiro, a matriz de todos os animais; em segundo, a matriz das plantas e, em terceiro

a matriz de todos os seres existentes.

Constituído por sinais fugazes, tinha milhares de paisagens, e uma só face,

nem viva, nem imortal. Não obstante, o seu encontro com o tempo apaziguara a velocidade aterradora do tempo,

esvaindo a arenosa substância da sua imagem. ${ }^{34}$

A escrita, anterior aos inícios, anterior às palavras. Mais, uma escrita não produzida pelo humano, ou divino, antes, a escrita que é um animal: matriz de tudo, força de plasmação do existente, animal anterior e cujo corpo é constituído por sinais, frágeis sinais vinculados ao passajar dos gestos escriturais: com corpo esfacelado e fragmentário, uma face que ultrapassa e extravasa o tempo, face "nem viva, nem imortal" a esvair e apaziguar sua "substância arenosa".

"Era uma vez": "à superfície das águas", 35 "no começar". ${ }^{36}$ Antes do tempo datável, uma palavra para sustentar o que não se inscreve no tempo e persiste; a linguagem mítica como erosão da certeza pelo apoiar-se no "animal escrita", e na leitura, ato sexual a que ele convoca. "Era uma vez", palavra inicial como confrontar e avançar na metamorfose da escrita que espera e, necessariamente, já estava lá como antecipação; relato originante que não cessa de evocar um tempo para um outro tempo, tempo ausente da origem, o fim sem fim do começar o segredo persistente da escrita:

[...] a "ausência de tempo" para a qual nos conduz a experiência literária não é, de modo algum a região do intemporal, e, se pela obra de arte somos chamados ao abalo de uma iniciativa verdadeira (a uma nova e instável aparição do fato de ser), esse começo nos fala na intimidade da história, de uma maneira que talvez dê chance a possibilidades históricas iniciais. ${ }^{37}$

Novas e iniciais possibilidades históricas, novos começos: o "era uma vez um animal" se dá como anúncio do começo e da criação dados no ato de leitura; e, como animal que já estava lá, seja como forma de cultura, seja como experiência
35. LLANSOL. Inquérito às quatro confidências, p. 95, destaques no original.

6AMPOS. Bere'shith. Gn1, 1-5, p.

7. BLANCHOT. O livro por vir, p. 290.
EM TESE
BELO HORIZONTE
v. 22
N. 2
MAIO-AGO. 2016
SAMUDIO. A superfície persistente do começar: escrita-leitura [...]
P. $245-254$ 
38. LLANSOL. Livro de Horas 1, p. 23

39. LOPES. Exercícios de aproximação, p. 205 dada no encontro com qualquer sujeito que, sob o seu signo, deseja se colocar, a escrita subsiste àquele que escreve, persistindo no seu começar. Uma "ausência de tempo", o "era uma vez", "à superfície das águas", "no começar”: sua leitura e escrita como entrada em uma cena primitiva que, trazendo à tona a origem do texto, é o próprio texto acontecendo:

\section{A vida eterna não existe.}

Sentou-se arranjando as saias, para assistir à produção do texto. Este texto é um texto que assiste à produção do texto.

Este texto é a cena primitiva do texto.

A mulher não existe, mas é escrita por

Texto que, no fim sem fim do mito, é um acontecer no seu aqui e no seu agora. A origem sempre distante e próxima, na escrita de Llansol, e não o retorno ou retomada de um passado histórico ou mítico narrado. Aproximação entre a narração e aquilo que se narra, em que "tudo se passa no 'agora' da efabulação, aquele em que se está a escrever-ler, pois nada importa pelo seu 'foi' ou 'será', mas pelo 'é' em que se cumpre, para sempre, pelo indizível confronto entre palavras, memórias e silêncios". ${ }^{39}$ Em Llansol, no fim sem fim do mito, a escrita, anterior ao início, é "palavra começante", "o movimento mais suave e mais secreto [...] porque nos empurra infinitamente para adiante, aquela que abala e que mais exige: [...] que nada dita, que a nada obriga, que nem sequer fala, mas faz desse silêncio o dedo imperiosamente fixo na direção do desconhecido" ${ }^{40}$

Escrita de um começar, no próprio texto. Escrita de um continuar, à superfície do texto. Escrita de um segredo, o desconhecido segredo: anterior ao início, anterior à narrativa do início, ela, a escrita: a superfície persistente do começar.

\section{REFERÊNCIAS}

BALTHASAR, Hans Urs von. Ensayos Teológicos: IV Pneuma e Institución. Trad. Eloy Rodriguez Navarro. Madrid: Encuentro, 2008.

BARTHES, Roland. Aula. Trad. Leyla Perrone-Moisés. São Paulo: Cultrix, 1979.

BIBLIA JERUSALÉM. São Paulo: Paulus, 2002.

BÍBLIA SAGRADA TRADUÇÃO DA CNBB. São Paulo: Loyola, 2002.

BLANCHOT, Maurice. La escritura del desastre. Trad. Pierre de Place. Caracas: Monte Ávila Editores, 1990

BLANCHOT, Maurice. O livro por vir. Trad. Leyla Perrone-Moisés. São Paulo: Martins Fontes, 2005.

BLANCHOT, Maurice. Uma voz vinda de outro lugar. Trad. Adriana Lisboa. Rio de Janeiro: Rocco, 2011.

BLANK, Josef. Espírito Santo/ Pneumatologia. In: EICHER, Peter (Org.). Dicionário de conceitos fundamentais de Teologia. Trad. João Rezende Costa. São Paulo: Paulus, 1993.
40. BLANCHOT. Uma voz vinda de outro lugar, p. 64. 
CAMPOS, Haroldo de. Bere'shith: a cena da origem (e outros estudos de poética bíblica). São Paulo: Perspectiva, 2000.

CASTELLO BRANCO, Lucia. Nuvens de pensamento branco. In: CASTELLO BRANCO, Lucia; ANDRADE, Vania Baeta (Org.). Livro de asas, para Maria Gabriela Llansol. Belo Horizonte: Editora UFMG, 2007. p. 227-252.

COSTA, Erick Gontijo. Curso de silêncio: a escrita das imagens curativas. Belo Horizonte: Faculdade de Letras da Universidade Federal de Minas Gerais, 2009 (Dissertação, Mestrado em Teoria da Literatura e Literatura Comparada).

COUTO, António José da Rocha. Narrativas da Criação. Igreja e missão. n. 192-193 (2003), p. 3-58. Vila Nova de Gaia Portugal.

DAUTZENBERG, G. Espírito; BAUER, Johannes. Dicionário Bíblico-Teológico. Trad. Fredericus Antonius Stein. São Paulo, Loyola, 2000, p. 126-136.

KOUBETCH, Volodemer. Da Criação à Parusia. São Paulo: Paulinas, 2004

LACAN, Jacques. O Seminário: 23, O Sinthoma. Trad. Sérgio Laia. Rio de Janeiro: Zahar, 2007.

LLANSOL, Maria Gabriela. Causa Amante. Lisboa: Relógio d'Água, 1996. LLANSOL, Maria Gabriela. Entrevistas. Belo Horizonte: Autêntica, 2011.

LLANSOL, Maria Gabriela. Inquérito às quatro confidências Belo Horizonte: Autêntica, 2011.
LLANSOL, Maria Gabriela. Lisboaleipzig I: O encontro

inesperado do diverso. Lisboa: Rolim, 1994.

LANSOL, Maria Gabriela. Livro de Horas 1: Uma data em cada mão. Lisboa: Assírio \& Alvim, 2009.

LANSOL, Maria Gabriela. Na Casa de Julho e Agosto. Lisboa: Relógio d'Água, 2003.

LLANSOL, Maria Gabriela. Parasceve. Lisboa: Relógio d'Água, 2001

LLANSOL, Maria Gabriela Um Falcão no punho Belo Horizonte: Autêntica, 2011.

LLANSOL, Maria Gabriela. O sonho de que temos a linguagem diário). Colóquio/ Letras, Lisboa, Fundação Gundabenkian, n. 143-144, jan.-jun. 1997, p. 5-18.

LOPES, Silvina Rodrigues. Exercícios de aproximação. Lisboa: Vendaval, 2003

RICOEUR, Paul. Le Volontaire et I'Involontaire. Paris: Aubier Montaigne, 1967.

ROCHA, João Alves. Ética da paisagem. Em Tese, Belo Horizonte, v. 21, n. 3, set.-dez. 2015, p. 90-103.

SAMUDIO, Jonas Miguel Pires. 0 há de escrever: a poética figural em Inquérito às quatro confidências, de Maria Gabriela Llansol. 2015. Dissertação (Mestrado em Estudos Literários) -

Uberlândia: Instituto de Letras e Linguística, 2015. 